\title{
COVID-19 vaccinations for seafarers on ocean-going vessels
}

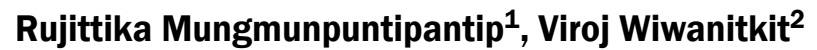

${ }^{1}$ Private Academic Consultant, Bangkok Thailand

${ }^{2}$ Honorary Professor, Dr DY Patil University, Pune, India

We would like to share ideas on the publication "Procedural aspects of COVID-19 vaccinations for seafarers on ocean-going vessels [1]." Schlaich et al. [1] mentioned that "As a port medical clinic, we will share our practical vaccination experience on board of merchant vessels in (...) published by the International Chamber of Shipping (www.ics-shipping.org) [1]." We recognise importance of vaccination for seafarers and a good procedure is very important. However, there are many practical issues for consideration. First, the flexibility of vaccine schedule is an important query. Seafarers might have to wander around and it might not possible to get a booster dose of vaccine on the appointed date and the same vaccine as the first dose might not be available in the new setting. Second, the pre-administration quality control of COVID-19 is important. How to deliver the vaccine to the site has to be specifically planned. In a large medical centre where there are plenty of facilities to promote cold chain delivery, the poor quality of the vaccine due to poor pre-administration keeping and delivery is still possible [2].

\section{Conflict of interest: None declared}

\section{REFERENCES}

1. Schlaich CC, Lucas K, Sydow S, et al. Procedural aspects of COVID-19 vaccinations for seafarers on ocean-going vessels. Int Marit Health. 2021; 72(3): 179-182, doi: 10.5603/MH.2021.0034, indexed in Pubmed: 34604986.

2. Mungmunpuntipantip R, Wiwanitkit V. Coronavirus disease 2019 (COVID-19) infection of healthcare personnel after complete COVID-19 vaccination. Infect Control Hosp Epidemiol. 2021 [Epub ahead of print]: 1, doi: 10.1017/ice.2021.404, indexed in Pubmed: 34486509 . 